\title{
The Power of Being Small: Nanosized Products for Agriculture
}

*Corresponding author

Tel: +435-797-2576

E-mail: annejanderson33@gmail.com ORCID

https://orcid.org/0000-0002-0463-2174

Received April 21, 2018

Revised April 30, 2018

Accepted May 1, 2018

\author{
Anne J. Anderson (1D* \\ Department of Biological Engineering, Utah State University, Logan, UT 84322-5305, USA
}

\begin{abstract}
Certain agrochemicals may be tuned for increased effectiveness when downsized to nanoparticles (NPs), where one dimension is less than $100 \mathrm{~nm}$. The NPs may function as fertilizers, pesticides and products to improve plant health through seed priming, growth promotion, and induction of systemic tolerance to stress. Formulations will allow targeted applications with timed release, reducing waste and pollution when compared to treatments with bulk-size products. The NPs may be a single component, such as nano-ZnO as a fertilizer, or be composites of compatible materials, for example where $\mathrm{N}, \mathrm{P}$, and $\mathrm{K}$ plus micronutrients are available. The active materials could be loaded into porous carriers or tethered to base nanostructures. Coatings could include such natural products alginate, chitosan, zein, or silica. Certain NPs are taken up and transported in the plant's phloem and xylem so systemic effects are feasible. Timed and targeted release of the active product could be achieved in response to changes in $\mathrm{pH}$ or availability of ligands within the plant or the rhizosphere. Global research has revealed the many potentials offered by NP formulations to aid sustainability in agriculture. Current work will provide information needed by regulatory agencies to assess their safety in the agricultural setting.
\end{abstract}

Keywords: Nanoparticles, Nanosize, Nanofertilizers, Nanopesticides, Plant growth and immuno stimulants

\section{Introduction}

Nanotechnology may help build sustainability into agriculture. The world's increasing human population requires quality foods and plant products. However, tracts of productive soil are limited, and increasing urban encroachment on agricultural lands restricts practices. Irrigation waters are becoming more saline and climate variability in temperature, storm frequency and intensity imposes threats to reliable harvests (Pierret and Lacombe, 2018). Currently chemicals are mainstay in the practices chosen for large scale pest control and fertilization contributing to higher agricultural yields. This review discusses their replacement by nanoformulations.

Research in Plant Disease

pISSN 1598-2262, elSSN 2233-9191

www.online-rpd.org
Nanoparticles (NPs) are defined as particles with at least one dimension less than $100 \mathrm{~nm}$. However, this definition is loosely applied in research and commerce with overlap into colloidal dimensions. The small size of NPs increases their surface area enhancing reactivity on a mass basis (Hartland et al., 2013). Thus, they have properties that differ from their bulk materials. Benefits of nanoproducts for agriculture would include more sophisticated targeted- and timereleased products. Additionally reduction in the levels of application of nanoformulations compared to bulk products would extend the worlds dwindling supplies of certain essential elements (Henckens et al., 2016) as well as reduce environmental pollution caused by broadcast applications that have an impact on nontarget sites. Phosphate and nitrogen pollution are current problems caused by fertilizer mismanagement (Cooper et al., 2010; EPA, 2018). Pesticide residues within soil and evolution of resistance to such chemicals by the target organisms additionally intensify the current drive 
for alternative tools to control crop pests.

\section{NP Composition and Commercialization Issues}

As nanotechnology advances there is a continuum of publications discussing the potential for nanoformulations to benefit agriculture (Chhipa, 2017; Duhan et al., 2017; Sekhon, 2014; Servin and White, 2016; Shalaby et al., 2016; Siddiqi and Husen, 2017; Yadav et al., 2014). Notable is the ability to increase productivity from marginal soils by supply of the major elements, nitrogen $(\mathrm{N})$, phosphate $(\mathrm{P})$ and potassium $(K)$ as well as minor elements, such as essential metals, Si and B. Such formulations are termed nanofertilizers. Other nanosized products could be formulated as pesticides. Several reviews include discussions on further niche products that are dependent on nanotechnology, for example nanobased methods for detection of viral pathogens (Duhan et al., 2017), water purification and remediation of contaminants (Parisi et al., 2015). However, this review is focused on strategies to improve plant health and performance (Fig. 1). Summarized in Table 1 are examples, from the abundant literature, summarizing potential agricultural use of nanoparticles (NPs). After a general introduction to NPs and plants, each of the potential uses of the NPs is discussed in sections: NPs as fertilizers, NPs as pesticidesand NPs that improve plant health through other mechanisms.

\section{NPs and Plant Interactions}

Particles of nanosize are naturally present in the environment (Biswas and Wu, 2005; Hartland et al., 2013; Sharma et al., 2015). Often airborne particles, such as carbon-containing composites from combustion, are studied because of their activity as pollutants affecting human health (Chen et al., 2008; Maher et al., 2016). Natural nanostrutures in water include those of plant origin which are biocompatible and could be used as carriers for nanoformulated-bioactive materials (Huang et al., 2015; Wang et al., 2016b). Soils contain many varied colloids and nanosize particles such as soil humic fractions or iron oxides that function in soil productivity (Hartland et al., 2013; Wilson et al., 2008). Nanoparticles are, thus, part of the environment where plants survive.

Uptake and systemic transfer of certain 'inert' NPs throughout the plant is demonstrated. For example, CuO NPs are distributed after root uptake in maize through the xylem to the shoots and back to the roots through the phloem (Wang et al., 2012a). Fluorescently labelled silica NPs travel both

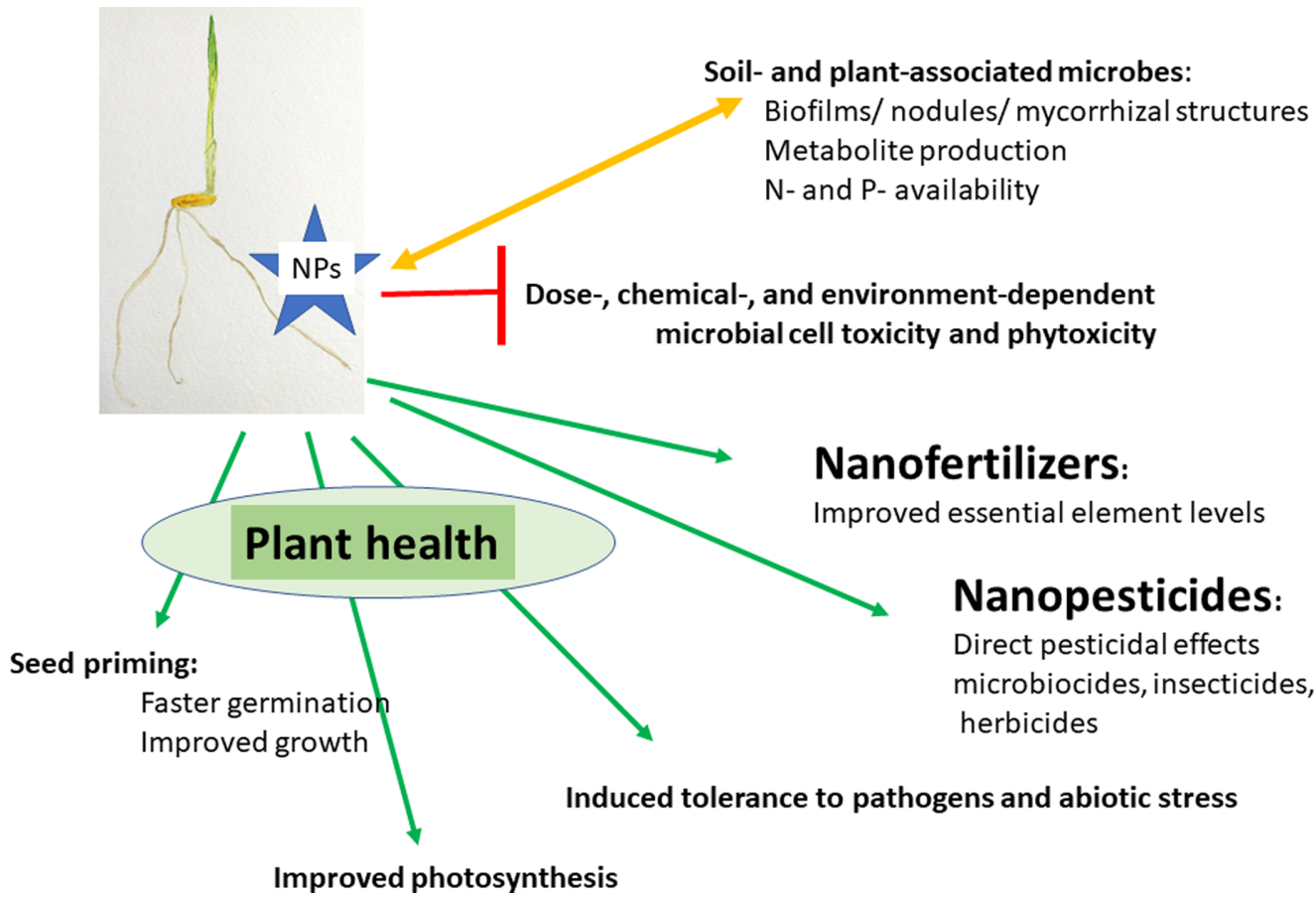

Fig. 1. Potential uses of nanoformulations in agriculture. 
Table 1. Summary of major potential uses of nanoparticles for agriculture. Examples of pertinent references are provided

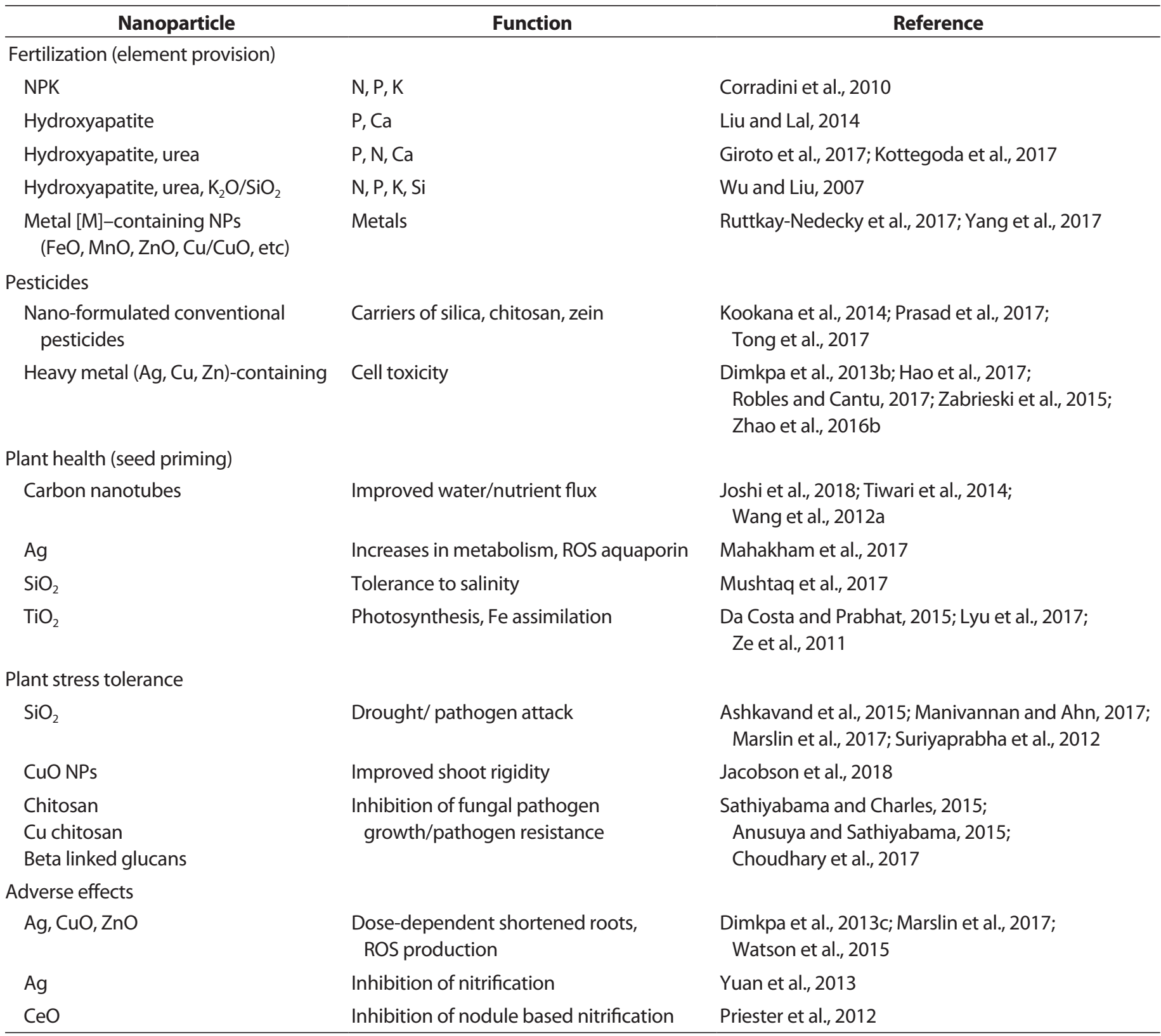

symplastically and apoplastically from roots to reach the xylem with subsequent transport to shoots (Sun et al., 2014). Work with $\mathrm{TiO}_{2}$ NPs (Larue et al., 2012) suggests that particles less than $140 \mathrm{~nm}$ diameter can enter wheat roots but only smaller particles, less than $36 \mathrm{~nm}$, gain access to the vasculature to be transported to shoots. Zein particles also travel to leaves after root exposure of soybean in hydroponic growth (Ristroph et al., 2017). Thus, contact, uptake and flux of NPs through plant tissues is a likely a common occurrence. However, the doses of NPs purposely applied to soils and plants will probably be localized and higher than those of natural origin. Also, phytotoxic responses may occur if the particles dissociate or react to release toxic materials, such as heavy metal ions. For example, in wheat, Cu ligands also are found in the shoots from seedling growth with root exposure to $\mathrm{CuO}$ NPs, indicating that limited dissolution of the NPs occurs (Dimkpa et al., 2013a).

The current task is to now engineer agricultural NPs that boost plant productivity with maximal efficacy and minimal environmental and health risks. The promise of the benefits of the nanoproducts have to be resolved from some of the problematic issues raised by the current research (Servin 
and White, 2016). For instance, many metal-containing NPs display dose- and $\mathrm{pH}$ - dependent phytotoxicity (RuttkayNedecky et al., 2017; Yang et al., 2017). Additionally, there are regulatory issues for their commercial application (Kah, 2015; Kookana et al., 2014; Parisi et al., 2015; Stone et al., 2010) ; these papers indicate how regulatory concepts differ between countries.

\section{Formulation of NPs}

NPs can be formulated from a single chemical as well as a complex of multiple active materials or active complex associated with carrier products (Fig. 2). For example, NPs composed only of zinc oxide or iron oxides could be used to boost zinc or iron levels respectively in planta in soils that have low bioavailability of these metals. Other NPs have inert structures where the NPs are tethered or held within channels. Simplistic examples of these potential structures are illustrated in Fig. 2. Coating additionally could be important in regulating the integrity of the formulation through maintenance of single particle rather than aggregated structures. Aggregation would downplay the advantage of heightened activity because of the high surface area/mass of the nanostructure (Hartland et al., 2013). Coating the active chemical, such as a pesticide, also could restrict unwanted effects in the environment while being beneficial for shelf life.

A current research thrust is to derive the NPs through 'green' and 'energy-effective' synthetic methods. For instance, Ag NPs can be derived by reduction of Ag ions using plant or microbial products that act as reductant and provide capping materials (Rai et al., 2015). Purification of the NPs to remove contaminating starting materials that, for instance, may contribute to extremes of $\mathrm{pH}$ of the formulations, seems to be an issue that is little studied especially for large scale production (Ruttkay-Nedecky et al., 2017).

Tools to characterize the NPs are essential. However much of the instrumentation is limited in availability with high cost and require operation by dedicated staff. Methods to size particles may include dynamic light scattering, atomic force microscopy, cryo-electron microscopy, and fast flow fractionation. Analytical chemistry technologies will determine purity and composition and crystallinity may be revealed by Xray diffraction. Small angle $X$-ray scattering will provide more detailed information on structural conformations. Surface charge analysis, determined for example by zeta potential measurements, is important in prediction of agglomeration because high positive or negative charges promote particle stability. FTIR and Raman spectroscopy may be used to determine compounds and structures associated with composite particles. However, it is difficult to assay location and concentrations of NPs in planta and in soils. Current scanning electron microscopy will detect only aggregates of the NPs and EDS will show their element composition but not their complexation. A combination of synchrotron-radiation
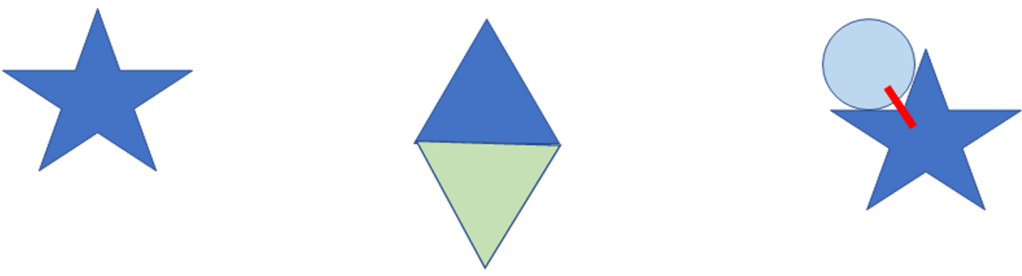

Uncoated, single component

Uncoated, mixed components

Tethered component

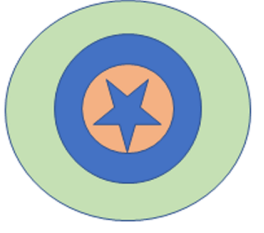

Coated/encapsulated mixed or single components

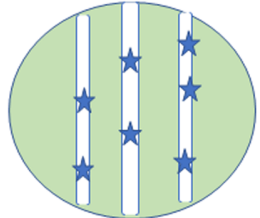

Trapped component

Fig. 2. Schematics of potential agronanoparticle structures. 
micro-X-ray fluorescence, transmission electron microscopy and micro-particle-induced X-ray emission successfully tracks distribution of intact $\mathrm{TiO}_{2}$ NPs from roots to shoots (Larue et al., 2012). The problems of ready tools for physical and chemical and locational analysis are part of the issues making the resolution of regulation for NP products complex.

Another issue for regulation is the lack of defined methods for assessment of potential toxic effects of NPs on plants, soil ecosystems and ultimately all of the environment including man. Fore mount in concerns over registration is knowledge of the impact of the NPs during manufacturing, packing, and then application of the NPs in the field to the humans involved in each of these processes. For instance, filtration masks and hoods will not trap particles of nano-size. Further, studying just the plant or its microbiome are not sufficient because of the complex food webs in which plants are raised. The biological factors that include plant growth and the 'call and response' metabolic changes between the plant and their associated soil microbiomes means that interactions between NPs and plants are dynamic and in flux. Adding to the difficulties in modelling fate and risk of the roles of NPs in agriculture is the fact that studies will vary with plant, cultivar and soil type. Variability in NP sources and their modes of preparation used by the research groups confound the issues. The development of new standards to assess risk to plants has been suggested from the times of earlier nano-agricultural research (e.g., Stampoulis et al., 2009). Because nanotechnology is relatively new, most stud- ies have been performed under model growth conditions with plants grown under pot or hydroponic culture and only short-term studies involving seed germination and young seedlings. Thus, currently, there is a lack of understanding of effects of large scale NP agricultural applications where there is the vast array of commercial plants grown in different soils under various climatic conditions. With these caveats, this review is written to show the potential impacts of nanotechnology to agriculture.

\section{NPs as Fertilizers}

Soil properties and cropping regimes determine the use of fertilizers for agricultural crops. Supplementation with Nitrogen-Phosphate-Potassium (NPK) as bulk sources from varied chemicals (e.g., nitrate, ammonia and urea for $\mathrm{N}$ ) is common. Augmentation of soils with other essential elements, such as Fe, Zn, Cu Mg and Mn, has the potential to become more important with soils that are intensively cropped along with postharvest removal of plant material. Currently, with application of bulk NPK, high proportions are lost into the environment rather than being utilized by the plant. Values for wasted product are $40-70 \%$ for $\mathrm{N}, 80-90 \%$ for $\mathrm{P}$, and 50 $70 \%$ for K (Duhan et al., 2017). The use of nanofertilizers may reduce these losses. The direct uptake and use of the NPs, or their released products may be involved dependent on size and formulation (Fig. 3).

Each of these plant-essential elements could be engi-

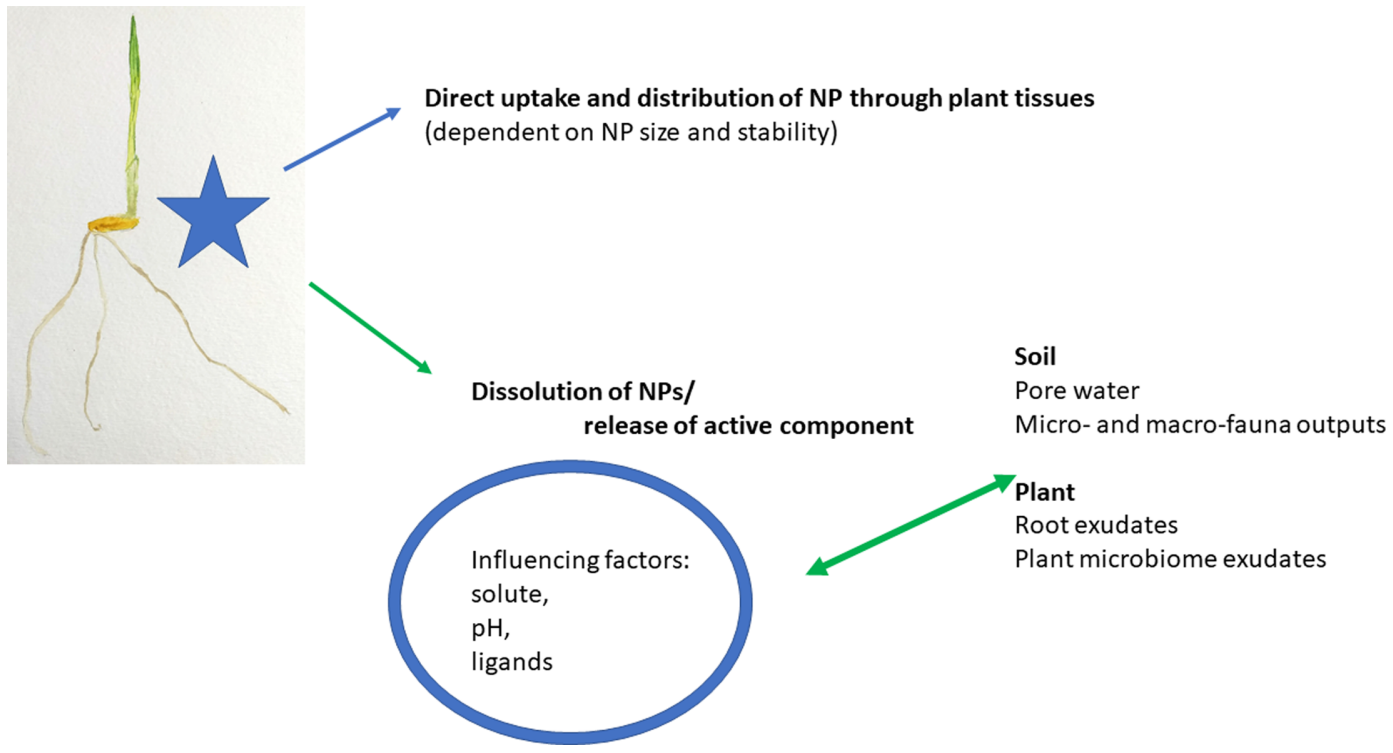

Fig. 3. Factors involved in plant responses to NP applications. 
neered to be present in simple or composite NPs (Fig. 2). For example, a mix containing urea, calcium phosphate, and potassium chloride, successfully binds to chitosan NPs to provide a nanoformulation for NPK application (Corradini et al., 2010). Chitosan is one of the preferred NP coatings because of its biocompatibility and degradation in a soil environment. Thus, it offers slow, long term release of associated structures, such as the chemicals providing NPK in the NPs (Corradini et al., 2010).

NPs containing phosphate successfully increase plant $P$ levels. In soybean, pure hydroxyapatite particles (mean $16 \mathrm{~nm}$ diameter) increased soybean growth rate and yield more than bulk $\mathrm{Ca}\left(\mathrm{H}_{2} \mathrm{PO}_{4}\right)_{2}$ (Liu and Lal, 2014). Use of hydroxyapatite as a $\mathrm{P}$ source when integrated with urea or a thermoplastic starch/urea polymer to form composite NPs shows good release of both urea and $\mathrm{P}$ upon treatment with citric acid, an acid common in plant root exudates. Long term release of $\mathrm{P}$ in soils is observed with these particles (Giroto et al., 2017). Such composites may reduce the loss of $\mathrm{N}$ as ammonia from the urea. A similar urea-hydroxyapatite nanohybrid is documented for slow release of $\mathrm{N}$ from the urea (Kottegoda et al., 2017). Greater rice yield was observed in farming conditions with application of a two-fold less $\mathrm{N}$ application than the recommended urea for this nanoformulation (Kottegoda et al., 2017). Similarly, layered NPs of $\mathrm{K}_{2} \mathrm{O}$, $\mathrm{SiO}_{2}$ and hydroxyapatite coated with a kaolin-based polymer slowly release K and Si (Wu and Liu, 2007). This formulation has additional interest because of its ability to swell and re- tain water to an extent of $85 \%$ of its own mass, thus, having the potential to modify water status in the soil (Wu and Liu, 2007). One commercial product, described at http://www. urthagriculture.com/nano-ag-fertilizer/, has nanosized particles of NPK, integrated with organic matter/electrolytes and beneficial microbes.

Increased levels of the essential metals occur in plants with applications of nanosized particles of metal oxides and the metals through uptake followed by transport. Uptake of intact particles into the plant, thorough the cuticle, stomates, and at lateral root emergence zones or wounds, is implicated for foliar and root applications (Ruttkay-Nedecky et al., 2017). Debate continues on the relevant role of the intact NP versus ions released from the NPs on the outcome of the plant responses. When metal exposure for the essential metals exceeds a threshold, phytotoxicity is observed (Ruttkay-Nedecky et al., 2017; Yang et al., 2017). Thus, dose would need to be tuned to environmental conditions especially those that boost NP dissolution and/or the release of the active compound (Fig. 4). For instance, doses of $\mathrm{CuO}$ NPs provided to wheat are more phytotoxic in acidic rather than calcareous soils, in part because of acidic $\mathrm{pH}$ promotes higher release of $\mathrm{Cu}$ ions (Anderson et al., 2017b; Watson et al., 2015). Ligands for the metal ions present in plant root exudates and soil pore waters, such as the organic acids, or the siderophores from monocots and microbes, also influence dissolution and the metal bioavailability of any complex (Adeleye et al., 2014; Hortin, 2017; Huang et al., 2017). Addi-

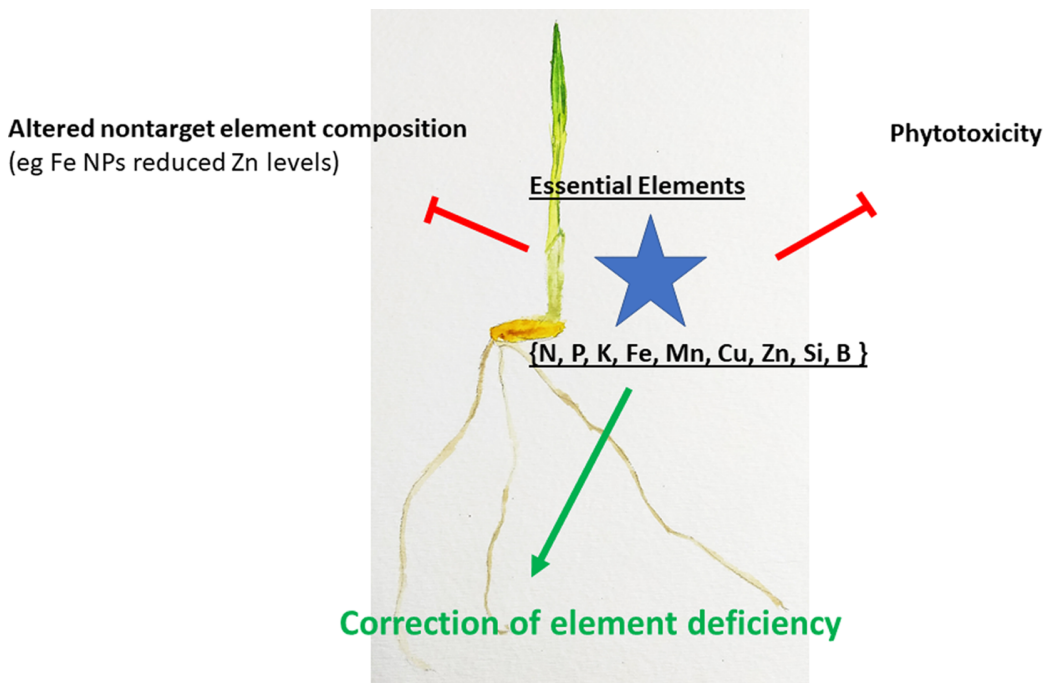

Fig. 4. Potential roles and problems with nutrient-containing NPs. 
tionally, the sensitivity of the plant to the element would be another factor; some plants have evolved effective mechanisms of resistance to heavy metals which likely would lead to different responses to NPs containing these metals.

Nanoformulation of the simple metal compounds, zerovalent iron or iron oxides, $\mathrm{Cu}$ and $\mathrm{CuO}, \mathrm{MnO}$ and $\mathrm{ZnO}$, are among the most studied as the bases to boost the plant's essential elements (Ruttkay-Nedecky et al., 2017; Yang et al., 2017). However, formulation may be tuned dependent on plant responses. In tomato, zerovalent iron NPs did not reduce root water uptake nor cause lower Mo and $\mathrm{Zn}$ shoot levels compared with the responses to $\mathrm{Fe}_{2} \mathrm{O}_{3} \mathrm{NPs}$ (MartínezFernández and Komárek, 2016). However, shoot $\mathrm{Ca}, \mathrm{K}$, Mg and S are lowered causing lower chlorophyll levels (MartínezFernández et al., 2016). Soybean leaf phosphate is noted to increase after applications of $\mathrm{Fe}_{3} \mathrm{O}_{4} \mathrm{NPs}$ that cause improved growth (Burke et al., 2015). Both Fe and S were bioavailable from $\mathrm{FeS}_{2} \mathrm{NPs}$ with synergism in greater growth and yield for several vegetables (Das et al., 2016). Similarly, maghemite NPs were more effective in Fe supply to Brassica napis than chelated iron (Palmqvist et al., 2017).

Interestingly, an application of ZnO NPs also increased plant $P$ accumulations in mung bean (Raliya et al., 2016). The suggested mechanism is that the release of $\mathrm{Zn}$ from the $\mathrm{ZnO}$ NPs stimulated the activity of the plant's phosphatase leading to greater release of $\mathrm{P}$ from insoluble rock phosphate for plant uptake. Thus, beneficial effects may accrue from more than just better nutrition from supply of an essential element directly from the NPs. This issue will be discussed further in the section on plant health benefits.

\section{NPs as Pesticides}

NPs with pesticidal activity are based on inherent toxic property of the compounds within their formulations. They may involve loaded carriers with formulations from emulsions and suspensions of nanocapsules (Kookana et al., 2014). Each of the formulations brings different risk parameters that need evaluation but the attraction of nanoformulation is that they will lessen nontarget effects and reduce contamination into the environment (Walker et al., 2017). Whether the pesticides gain entry into the plant as the particle and then are released, or whether they are active while associated with the plant's surface would be NP-dependent (Fig. 3). Carriers used for the pesticide-loaded NPs include porous nanosized silica particles, gels and natural products, such as zein and chitosan (Kookana et al., 2014; Prasad et al., 2017; Tong et al., 2017). The encapsulated materials include common pesticides such as the herbicides, e.g., 2,4-D, glyphosate and sulfonylurea, or bacteriocides and fungicides (Kookana et al., 2014). For instance, a nanoproduct active on the fungal pathogen Alternaria alternata containing the commercial fungicides zineb and mancozeb formulated with functionalized carbon nanotubes, has greater activity than the bulk pesticides (Sarlak et al., 2014).

The toxicity of heavy metals to microbes makes NPs containing these materials logical choices as candidates for pesticides. These metals exert their toxicity in part by causing accumulation of reactive oxygen species (ROS) in the cell and by inhibition of key enzymes that have reactive sulfhydryl groups (Shahid et al., 2014; Tang et al., 2016). Because the toxicity of metal-containing NPs in part is correlated with their release of metal ions, processes that enhance NP-dissolution are important. Metal ligands (organic acids, amino acids, siderophores) and pH feature in these interactions. In vitro studies readily demonstrate nanosized-products containing $\mathrm{Ag}, \mathrm{Cu}$ and $\mathrm{Zn}$ directly inhibit growth of microbial plant pathogens (Dimkpa et al., 2013b; Robles and Cantu, 2017; Zabrieski et al., 2015). Dose-dependent effects of CuO NPs are noted in vitro and on infected leaves for a rose fungal pathogen (Hao et al., 2017).

The application of nanopesticides also may have nontarget effects (Ruotolo et al., 2018). The commercial micronized copper hydroxide fungicide/bacteriocide, Kocide, registered for organic and regular crop production, contains a range of particle sizes including into the nano range (Zhao et al., 2016b). Foliar applications of this product induce changes in lettuce leaf metabolism consistent with stress responses for heavy metal detoxification and protection against oxidative stress (Zhao et al., 2016a). Similarly, increased expression for genes involved with metal homeostasis and protection against ROS, is noted for applications of CuO NPs to wheat; these are coincident with altered root morphology (Adams et al., 2017; Yang et al., 2018). Studies with hydroponically grown cucumber shows that nano-Cu, used because of its potential as a fungicide/bacteriocide, reduces the loads of other essential elements, such as $\mathrm{Fe}, \mathrm{Zn}, \mathrm{S}$, and $\mathrm{P}$ in the plant (Zhao et al., 2016a). Reduced levels of Fe, Mn, Zn, and $\mathrm{Ca}$ are noted in bean shoots with $\mathrm{CuO}$ NPs exposure along with lowered activity of the root ferric oxidase (Dimkpa et al., 
2015a). These findings, as well as similar results from other NP studies (e.g., $\mathrm{Fe}_{2} \mathrm{O}_{3} \mathrm{NPs}$ cause reduction in plant $\mathrm{Zn}$, as reported by Martínez-Fernández and Komárek, 2016), are raising concern of altered nutritional properties if the plant was used as a food source.

\section{Improved Crop Health: Seed Priming}

NP treatment of plants often have consequences to plant health that differ from those defined as improved nutrition or direct inhibition of pathogen survival. Seed priming is a method used to promote seedling development, mainly through limited-time wetting to stimulate metabolic changes promoting germination (Paparella et al., 2015). Certain NPs appear to boost these priming effects. Seed priming with Ag NPs correlates with increased carbohydrate metabolism, induction of reactive oxygen species (ROS) and greater presence of aquaporins in cell membranes for transport of water and dissolved nutrients (Mahakham et al., 2017). Seed priming for wheat with multiwalled carbon nanotubes leads to faster germination and root growth with elongation of the root cells being observed (Wang et al., 2012a). These carbon nanotubes penetrate through the cell walls to be found in the cytoplasm. After wheat seed priming with multiwalled carbon nanotubes, the seedlings have enhanced root hair production and higher phosphate plant levels culminating in greater yields (Joshi et al., 2018). Growth enhancement through increased water/nutrient flux and changes in Fe redox is suggested to be involved in the stimulated growth of maize occurring with multiwalled carbon nanotubes (Tiwari et al., 2014). It is tempting to speculate that plant growth in soils post a fire event is stimulated by seed priming by combustion-generated carbon NPs.

Growth of wheat under conditions that would involve seed priming at NP doses that cause root shortening, also results in additional changes in root morphology involving root hair proliferation with $\mathrm{CuO}$ NPs and more lateral root development with ZnO NPs (Adams et al., 2017; Yang et al., 2018). These changes in root morphology are both strategies that could be beneficial for plant growth under certain field conditions (Yang et al., 2018). Thus, even metals, classified as essential for cells because of roles as cofactors in structures and enzymes, also act as players in regulating growth morphology.

\section{Beneficial Effects of Ti- and Si-Containing NPs}

A recent review (Lyu et al., 2017) posits that Ti is an essential element for plants, with Ti promoting systems for Fe assimilation by plants growing under low Fe conditions. Beneficial effects of $\mathrm{TiO}_{2} \mathrm{NPs}$ are reported. Improved photochemical reactions are seen in spinach chloroplasts occur with $\mathrm{TiO}_{2}$ NPs (Hong et al., 2005). Similarly, increases in photosynthetic potential are observed in Arabidopsis leaves with $\mathrm{TiO}_{2}$ applications and are attributed to effects on light harvesting complex II (Ze et al., 2011). However, there are conflicting data with decreases in photosynthesis being documented for rice (Da Costa and Prabhat, 2015).

Another nonessential element beneficial for plants is $\mathrm{Si}$, especially where repeated cropping of soils has depleted the bioavailable silicates. A central role of silica, $\mathrm{SiO}_{2}$, in ameliorating plant stress to drought and pathogen attack is proposed (Luyckx et al., 2017; Manivannan and Ahn, 2017). Silica treatments promote upregulation of expression of genes involved in pathogen resistance and protection of photosynthesis (Manivannan and Ahn, 2017). Applications of porous silica NPs improve maize growth (Suriyaprabha et al., 2012). Seed priming with silica NPs enhances germination leading to seedlings with higher tolerance to growth under saline conditions (Mushtaq et al., 2017) and seedling growth with the silica NPs leads to drought tolerance (Ashkavand et al., 2015). Additionally, porous $\mathrm{SiO}_{2} \mathrm{NPs}$ may pack increased beneficial effects by their transport of plant-active compounds, such as antibiotics or plant growth hormones.

\section{NPs for Stimulating Plant Resistance Responses}

Stimulation of pathogen-resistance responses occurs after challenge of plant tissues with an array of compounds. Fungal cell wall structures including chitosan and glucans are such elicitors (Chandra et al., 2015). NPs made from chitosan, isolated from walls of the fungal pathogen Fusarium oxysporum f. sp. lycopersici, triggered resistance in tomato against infection by this pathogen (Sathiyabama and Charles, 2015). Nano-formulation of the eliciting cell wall polymers, beta 1,3-glucans, display antifungal activity (Sathiyabama and Charles, 2015) and induce resistance in tumeric rhizomes against Pythium infections (Anusuya and Sathiyabama, 
2015). Activation of plant defense mechanisms also occurs with chitosan particles amended with nano-Cu (Choudhary et al., 2017), where both the chitosan and Cu could exert protective responses in the plant.

Other beneficial effects are associated with the NP treatments include improved plant growth and carbohydrate metabolism (Choudhary et al., 2017; Saharan et al., 2016), enhanced flavor (Pinedo-Guerrero et al., 2017), as well as protection against salinity stress (Hernández-Hernández et al., 2018). Thus, these studies strengthen the concept of overlap in the activation of plant defense and abiotic stress tolerance mechanism with improved plant growth. As evidenced in this review these goals are achievable by plant treatments with many different types of NPs.

\section{NPs Effects on the Plant and Soil Microbiome}

As well as influencing the plant, applied NPs will affect both plant and soil microbiomes. Shifts in the microbiomes by some NPs are found using nonculturable techniques at the genera/species level but the consequences of these changes is often not revealed (Rousk et al., 2012). However, there are effects on major element cycling pathways: Ag NPs impair microbial nitrification, an effect of special concern in waste water processing (Yuan et al., 2013). Also, studies with soybean show that $\mathrm{CeO}$ NPs, but not ZnO NPs, hinder bacterial nitrogen fixation through impaired nodule function (Priester et al., 2012).

Dose-dependent changes in metabolism of a beneficial root-colonizing bacterium, $P$. chlororaphis $\mathrm{O} 6$ are observed at sublethal NP doses. For example, ZnO NPs induce formation of a metal-chelating siderophore, but reduce production of antifungal phenazines (Goodman et al., 2016). Significantly, the ZnO NPs impair production of the acyl homoserine lactones, which are signals regulating the production of these and other metabolites with functions in the rhizosphere (Anderson et al., 2017a; Goodman et al., 2016). Increased production of the pseudomonad siderophore is observed from wheat roots colonized by $P$. chlororaphis $\mathrm{O} 6$ when growing with ZnO NPs (Dimkpa et al., 2015a). However, the consequences of such changes in cell signaling for these important rhizosphere processes awaits investigation.

Not all root-microbe interactions are negatively affected. Root association with the beneficial fungi, mycorrhizae, appear to be protective against damaging doses of such NPs as $\mathrm{ZnO}$ NPs, until a threshold of toxicity is reached (Wang et al., 2016a). No effects on mycorrhizal colonization are reported for applications of iron oxide or $\mathrm{TiO}_{2}$ on soybean (Burke et al., 2015). Also, colonization of bean root surfaces by the beneficial soil bacterium, $P$. chlororaphis $\mathrm{O6}$, is not impaired by nanoCuO and nanoZnO on bean (Dimkpa et al., 2015b). Root colonization by $P$. chlororaphis $\mathrm{O} 6$ involves formation of patchy biofilms and this process is not impeded when wheat is grown with these NPs (Jacobson et al., 2018). Additionally, $P$. chlororaphis $\mathrm{O} 6$ colonization still induced drought tolerance in wheat during seedling growth with $\mathrm{CuO}$ or $\mathrm{ZnO}$ NPs (Jacobson et al., 2018; Yang et al., 2018). Transcript analysis with these plants show certain protective genes for stress

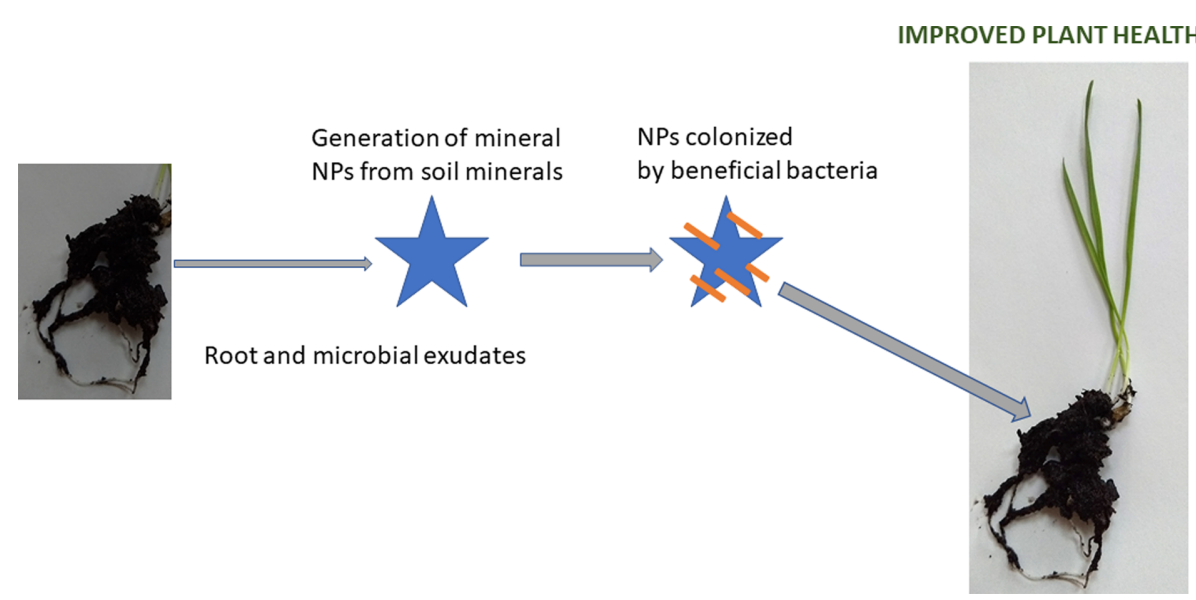

Fig. 5. Potential positive roles of NPs in improving plant health. Plant health is improved through interaction of NPs colonized by beneficial microbes. The NPs may result from effects of plant root and microbial exudates in the rhizosphere on larger particulate minerals in the soil. Adapted in part from Timmusk et al., (2018). 
caused by drought or pathogen challenge were more highly upregulated in the colonized NP-grown plants compared with treatment by the bacterium or NPs alone (Wright et al., 2016; Yang et al., 2018). It is possible that in planta stimulation of ROS by the NPs contributes to onset of the plant's broad stress tolerance responses (Jacobson et al., 2018; Marslin et al., 2017).

Recent studies with $\mathrm{TiO}_{2} \mathrm{NPs}$ find that the nanostructures play a positive role in by providing colonization sites for beneficial Gram-positive bacteria. The improved attachment of Bacillus amyloliquifaciens to oil seed rape roots in the presence of the NPs correlates with systemic protection against leaf infection by Alternaria brassicae (Palmqvist et al., 2015). Similarly, increase tolerance to drought or pathogen stress, caused by Fusarium culmorum, is observed in wheat by the inclusion of $\mathrm{TiO}_{2} \mathrm{NPs}$ with inocula of other beneficial strains (Timmusk et al., 2018). They suggest that the NPs act to boost the potential of the root-colonizing microbiome to benefit the plant (Timmusk et al., 2018). An interesting scenario, outlined in Fig. 5 , is proposed where the organic acids in the rhizosphere may contribute to weathering of minerals in the soil to generate NPs (Seisenbaeva et al., 2013) that then provide large surfaces areas that become colonized by the plant beneficial bacteria (Timmusk et al., 2018). Both root- associated bacteria and NPs may interact further to boost this scenario through effecting the composition and quantities of root exudates contributing to NP origin from larger mineral particles in the soil (Hortin, 2017; Wright et al., 2016). For example, colonization by $P$. chlororaphis $\mathrm{O} 6$ increases gluconic acid in the rhizosphere (Wright et al., 2016). These interactive mechanisms likely reflect the long co-evolution of plants with NPs and beneficial microbes.

\section{Conclusions}

There is great promise for the use of nano-sized products in agriculture. Many engineered NPs are active in promoting nutrition and growth as well as resilience to pathogens and abiotic stress in the treated plants (Fig. 1). However, there are the problems of potential toxicity to nontarget organisms, including microbes involved in element cycling processes, as well as phytotoxicity. The issue of dosage and NP structure require extensive modelling and basic research to maximize effectiveness and minimize plant/environmental damage. Downstream effects of NPs in the aqueous ecosystems of rivers, lakes and oceans as well waste processing systems requires attention from teams that combine a range of expertise. However, the nanotechnology field has already moved swiftly with growing fruitful collaborations for engineering and characterization of the NP products with the biological and molecular understanding their impact on agricultural ecosystems. Future collaborations are needed to provide the data sets required for regulatory agencies to clear safety for humans and the environment as well as and effectiveness of the NPs in agriculture.

\section{Conflicts of Interest}

No potential conflict of interest relevant to this article was reported.

\section{Acknowledgement}

The author thanks Dr Y. C. Kim for advice and suggested edits of this paper. Many discussions with Dr. David Britt and Dr. Joan Mclean at Utah State University are appreciated. The hard work of undergraduate and graduate students associated with the Anderson laboratory aided in obtaining significant results included in this discussion and published papers. The author also thanks the many authors of stimulating papers read for this work. The work was supported in part by NIFA-USDA Grant Number 10867118 (2012-2015).

\section{References}

Adams, J., Wright, M., Wagner, H., Valiente, J., Britt, D. and Anderson, A. 2017. Cu from dissolution of $\mathrm{CuO}$ nanoparticles signals changes in root morphology. Plant Physiol. Biochem. 110: 108117.

Adeleye, A. S., Conway, J. R., Perez, T., Rutten, P. and Keller, A. A. 2014. Influence of extracellular polymeric substances on the long-term fate, dissolution, and speciation of copper-based nanoparticles. Environ. Sci. Technol. 48: 12561-12568.

Anderson, A. J., McLean, J. E., Jacobson, A. R. and Britt, D. W. 2017a. $\mathrm{CuO}$ and $\mathrm{ZnO}$ nanoparticles modify interkingdom cell signaling processes relevant to crop production. J. Agric. Food Chem. DOI: 10.1021/acs.jafc.1027b01302. (In press)

Anderson, A., McLean, J., McManus, P. and Britt, D. 2017b. Soil chemistry influences the phytotoxicity of metal oxide nanoparticles. Int. J. Nanotechnol. 14: 15-21.

Anusuya, S. and Sathiyabama, M. 2015. Protection of turmeric plants from rhizome rot disease under field conditions by beta- 
D-glucan nanoparticle. Int. J. Biol. Macromol. 77: 9-14.

Ashkavand, P., Tabari, M., Zarafshar, M., Tomášková, I. and Struve, D. 2015. Effect of $\mathrm{SiO}_{2}$ nanoparticles on drought resistance in hawthorn seedlings. Forest Research Papers 76: 350-359.

Biswas, P. and Wu, C. Y. 2005. Nanoparticles and the environment. J. Air. Waste Manag. Assoc. 55: 708-746.

Burke, D. J., Pietrasiak, N., Situ, S. F., Abenojar, E. C., Porche, M., Kraj, P. et al. 2015. Iron oxide and titanium dioxide nanoparticle effects on plant performance and root associated microbes. Int. J. Mol. Sci. 16: 23630-23650.

Chandra, S., Chakraborty, N., Dasgupta, A., Sarkar, J., Panda, K. and Acharya, K. 2015. Chitosan nanoparticles: a positive modulator of innate immune responses in plants. Sci. Rep. 5: 15195.

Chen, H., Goldberg, M. S. and Villeneuve, P. J. 2008. A systematic review of the relation between long-term exposure to ambient air pollution and chronic diseases. Rev. Environ. Health 23: 243297.

Chhipa, H. 2017. Nanofertilizers and nanopesticides for agriculture. Environ. Chem. Lett. 15: 15-22.

Choudhary, R. C., Kumaraswamy, R. V., Kumari, S., Sharma, S. S., Pal, A., Raliya, R. et al. 2017. Cu-chitosan nanoparticle boost defense responses and plant growth in maize (Zea mays L.). Sci. Rep. 7: 9754.

Cooper, P. F., McBarnet, W., O'Donnell, D., McMahon, A., Houston, L. and Brian, M. 2010. The treatment of run-off from a fertiliser plant for nitrification, denitrification and phosphorus removal by use of constructed wetlands: a demonstration study. Water Sci. Technol. 61: 355-363.

Corradini, E., de Moura, M. R. and Mattoso, L. H. C. 2010. A preliminary study of the incorparation of NPK fertilizer into chitosan nanoparticles. Express. Polym. Lett. 4: 509-515.

Da Costa, M. V. and Prabhat, K. S. 2015. Influence of titanium dioxide nanoparticles on the photosynthetic and biochemical processes in Oryza sativa. Int. J. Recent Sci. Res. 6: 2445-2451.

Das, C. K., Srivastava, G., Dubey, A., Roy, M., Jain, S., Sethy, N. K. et al. 2016. Nano-iron pyrite seed dressing: a sustainable intervention to reduce fertilizer consumption in vegetable (beetroot, carrot), spice (fenugreek), fodder (alfalfa), and oilseed (mustard, sesamum) crops. Nanotechnol. Environ. Eng. 1: 2.

Dimkpa, C. O., Hansen, T., Stewart, J., McLean, J. E., Britt, D. W. and Anderson, A. J. 2015a. ZnO nanoparticles and root colonization by a beneficial pseudomonad influence essential metal responses in bean (Phaseolus vulgaris). Nanotoxicology 9: 271278.

Dimkpa, C. O., Latta, D. E., McLean, J. E., Britt, D. W., Boyanov, M. I. and Anderson, A. J. 2013a. Fate of $\mathrm{CuO}$ and $\mathrm{ZnO}$ nano- and microparticles in the plant environment. Environ. Sci. Technol. 47: 4734-4742.

Dimkpa, C. O., McLean, J. E., Britt, D. W. and Anderson, A. J. 2013b. Antifungal activity of $\mathrm{ZnO}$ nanoparticles and their interactive effect with a biocontrol bacterium on growth antagonism of the plant pathogen Fusarium graminearum. Biometals 26: 913-
924.

Dimkpa, C. O., McLean, J. E., Britt, D. W. and Anderson, A. J. 2015b. Nano-CuO and interaction with nano-ZnO or soil bacterium provide evidence for the interference of nanoparticles in metal nutrition of plants. Ecotoxicology 24: 119-129.

Dimkpa, C. O., McLean, J. E., Martineau, N., Britt, D. W., Haverkamp, R. and Anderson, A. J. 2013c. Silver nanoparticles disrupt wheat (Triticum aestivum L.) growth in a sand matrix. Environ. Sci. Technol. 47: 1082-1090.

Duhan, J. S., Kumar, R., Kumar, N., Kaur, P., Nehra, K. and Duhan, S. 2017. Nanotechnology: the new perspective in precision agriculture. Biotechnol. Rep. 15: 11-23.

EPA. 2018. Nutrient pollution: the problem. URL https://www.epa. gov/nutrientpollution/problem/

Giroto, A. S., Guimaraes, G. G., Foschini, M. and Ribeiro, C. 2017. Role of slow-release nanocomposite fertilizers on nitrogen and phosphate availability in soil. Sci Rep 7: 46032.

Goodman, J., McLean, J. E., Britt, D. W. and Anderson, A. J. 2016. Sublethal doses of $\mathrm{ZnO}$ nanoparticles remodel production of cell signaling metabolites in the root colonizer Pseudomonas chlororaphis O6. Environ. Sci. Nano 3: 1103-1113.

Hao, Y., Cao, X., Ma, C., Zhang, Z., Zhao, N., Ali, A. et al. 2017. Potential applications and antifungal activities of engineered nanomaterials against gray mold disease agent Botrytis cinerea on rose petals. Front. Plant Sci. 8: 1332.

Hartland, A., Lead, J. R., Slaveykova, V. I., O'Carroll, D. and ValsamiJones, E. 2013. The environmental significance of natural nanoparticles. Nature Education Knowledge 4: 7.

Henckens, M. L. C. M., van lerland, E. C., Driessen, P. P. J. and Worrell, E. 2016. Mineral resources: geological scarcity, market price trends, and future generations. Resour. Policy 49: 102-111.

Hernández-Hernández, H., González-Morales, S., Benavides-Mendoza, A., Ortega-Ortiz, H., Cadenas-Pliego, G. and Juárez-Maldonado, A. 2018. Effects of chitosan-PVA and Cu canoparticles on the growth and antioxidant capacity of tomato under saline stress. Molecules 23: 178.

Hong, F., Zhou, J., Liu, C., Yang, F., Wu, C., Zheng, L. and Yang, P. 2005. Effect of nano- $\mathrm{TiO}_{2}$ on photochemical reaction of chloroplasts of spinach. Biol. Trace Elem. Res. 105: 269-279.

Hortin, J. 2017. Behavior of Copper Oxide Nanoparticles in Soil Pore Waters as Influenced by Soil Characteristics, Bacteria, and Wheat Roots. Biological Engineering, Utah State University, Logan, UT, USA.

Huang, Y., Zhao, L. and Keller, A. A. 2017. Interactions, transformations, and bioavailability of nano-copper exposed to root exudates. Environ. Sci. Technol. 51: 9774-9783.

Huang, Y., Wang, Y. J., Wang, Y., Yi, S., Fan, Z., Sun, L. et al. 2015. Exploring naturally occurring ivy nanoparticles as an alternative biomaterial. Acta Biomater. 25: 268-283.

Jacobson, A., Doxey, S., Potter, M., Adams, J., Britt, D., McManus, P. et al. 2018. Interactions between a plant probiotic and nanoparticles on plant responses related to drought tolerance. Ind. Bio- 
tech. (In press)

Joshi, A., Kaur, S., Dharamvir, K., Nayyar, H. and Verma, G. 2018. Multi-walled carbon nanotubes applied through seed-priming influence early germination, root hair, growth and yield of bread wheat (Triticum aestivum L.). J. Sci. Food Agric. 98: 31483160.

Kah, M. 2015. Nanopesticides and nanofertilizers: emerging contaminants or opportunities for risk mitigation? Front. Chem. 3: 64.

Kookana, R. S., Boxall, A. B. A., Reeves, P. T., Ashauer, R., Beulke, S., Chaudhry, Q. et al. 2014. Nanopesticides: guiding principles for regulatory evaluation of environmental risks. J. Agric. Food Chem. 62: 4227-4240.

Kottegoda, N., Sandaruwan, C., Priyadarshana, G., Siriwardhana, A., Rathnayake, U. A., Berugoda Arachchige, D. M. et al. 2017. Ureahydroxyapatite nanohybrids for slow release of nitrogen. ACS Nano 11: 1214-1221.

Larue, C., Laurette, J., Herlin-Boime, N., Khodja, H., Fayard, B., Flank, A. M. et al. 2012. Accumulation, translocation and impact of $\mathrm{TiO}_{2}$ nanoparticles in wheat (Triticum aestivum spp.): influence of diameter and crystal phase. Sci. Total Environ. 431: 197-208.

Liu, R. and Lal, R. 2014. Synthetic apatite nanoparticles as a phosphorus fertilizer for soybean (Glycine max). Sci. Rep. 4: 5686.

Luyckx, M., Hausman, J. F., Lutts, S. and Guerriero, G. 2017. Silicon and plants: current knowledge and technological perspectives. Front. Plant Sci. 8: 411.

Lyu, S., Wei, X., Chen, J., Wang, C., Wang, X. and Pan, D. 2017. Titanium as a beneficial element for crop production. Front. Plant Sci. 8: 597.

Mahakham, W., Sarmah, A. K., Maensiri, S. and Theerakulpisut, P. 2017. Nanopriming technology for enhancing germination and starch metabolism of aged rice seeds using phytosynthesized silver nanoparticles. Sci. Rep. 7: 8263.

Maher, B. A., Ahmed, I. A. M., Karloukovski, V., MacLaren, D. A., Foulds, P. G., Allsop, D. et al. 2016. Magnetite pollution nanoparticles in the human brain. Proc. Natl. Acad. Sci. U.S.A. 113: 1079710801.

Manivannan, A. and Ahn, Y. K. 2017. Silicon regulates potential genes involved in major physiological processes in plants to combat stress. Front. Plant Sci. 8: 1346.

Marslin, G., Sheeba, C. J. and Franklin, G. 2017. Nanoparticles alter secondary metabolism in plants via ROS burst. Front. Plant Sci. 8: 832.

Martínez-Fernández, D. and Komárek, M. 2016. Comparative effects of nanoscale zero-valent iron ( $\mathrm{nZVI}$ ) and $\mathrm{Fe}_{2} \mathrm{O}_{3}$ nanoparticles on root hydraulic conductivity of Solanum lycopersicum L. Environ. Exp. Bot. 131: 128-136.

Martínez-Fernández, D., Barroso, D. and Komárek, M. 2016. Root water transport of Helianthus annuus L. under iron oxide nanoparticle exposure. Environ. Sci. Pollut. Res. Int. 23: 1732-1741.

Mushtaq, A., Jamil, N., Riaz, M., Hornyak, G. L., Ahmed, N., Shabbir Ahmed Rana, S. et al. 2017. Synthesis of silica nanoparticles and their effect on priming of wheat (Triticum aestivum L.) under salinity stress. Biol. Forum. 9: 150-157.

Palmqvist, N. G., Bejai, S., Meijer, J., Seisenbaeva, G. A. and Kessler, V. G. 2015. Nano titania aided clustering and adhesion of beneficial bacteria to plant roots to enhance crop growth and stress management. Sci. Rep. 5: 10146.

Palmqvist, N. G. M., Seisenbaeva, G. A., Svedlindh, P. and Kessler, V. G. 2017. Maghemite nanoparticles acts as nanozymes, improving growth and abiotic stress tolerance in Brassica napus. Nanoscale Res. Lett.12: 631.

Paparella, S., Araújo, S. S., Rossi, G., Wijayasinghe, M., Carbonera, D. and Balestrazzi, A. 2015. Seed priming: state of the art and new perspectives. Plant Cell Rep. 34: 1281-1293.

Parisi, C., Vigani, M. and Rodríguez-Cerezo, E. 2015. Agricultural nanotechnologies: what are the current possibilities? Nano Today 10: 124-127.

Pierret, A. and Lacombe, G. 2018. Hydrologic regulation of plant rooting depth: breakthrough or observational conundrum? Proc. Natl. Acad. Sci. U.S.A. 115: E2669-E2670.

Pinedo-Guerrero, Z. H., Hernandez-Fuentes, A. D., Ortega-Ortiz, H., Benavides-Mendoza, A., Cadenas-Pliego, G. and Juarez-Maldonado, A. A. 2017. Cu nanoparticles in hydrogels of chitosan-PVA affects the characteristics of post-harvest and bioactive compounds of jalapeno pepper. Molecules 22: E926.

Prasad, A., Astete, C. E., Bodoki, A. E., Windham, M., Bodoki, E. and Sabliov, C. M. 2017. Zein nanoparticles uptake and translocation in hydroponically grown sugar cane plants. J. Agric. Food Chem. DOI: 10.1021/acs.jafc.1027b02487. (In press)

Priester, J. H., Ge, Y., Mielke, R. E., Horst, A. M., Moritz, S. C., Espinosa, K. et al. 2012. Soybean susceptibility to manufactured nanomaterials with evidence for food quality and soil fertility interruption. Proc. Natl. Acad. Sci. U.S.A. 109: E2451-E2456.

Rai, M., Maliszewska, I., Ingle, A., Gupta, I. and Yadav, A. 2015. Diversity of microbes in synthesis of metal nanoparticles: progress and limitations in bio-nanoparticles: biosynthesis and sustainable biotechnological implications. In: Bio-Nanoparticles: Biosynthesis and Sustainable Biotechnological Implications, ed. by O. V. Singh, pp. 1-30. Wiley-Blackwell.

Raliya, R., Tarafdar, J. C. and Biswas, P. 2016. Enhancing the mobilization of native phosphorus in the mung bean rhizosphere using $\mathrm{ZnO}$ nanoparticles synthesized by soil fungi. J. Agric. Food Chem. 64: 3111-3118.

Ristroph, K. D., Astete, C. E., Bodoki, E. and Sabliov, C. M. 2017. Zein nanoparticles uptake by hydroponically grown soybean plants. Environ. Sci. Technol. 51: 14065-14071.

Robles, C. and Cantu, M. 2017. Nanopesticides a real breakthrough for agriculture? Revista Bio. Ciencias. 4: 164-178.

Rousk, J., Ackermann, K., Curling, S. F. and Jones, D. L. 2012. Comparative toxicity of nanoparticulate $\mathrm{CuO}$ and $\mathrm{ZnO}$ to soil bacterial communities. PLoS One 7: e34197.

Ruotolo, R., Maestri, E., Pagano, L., Marmiroli, M., White, J. C. and Marmiroli, N. 2018. Plant response to metal-containing engi- 
neered nanomaterials: an omics-based perspective. Environm. Sci. Technol. 52: 2451-2467.

Ruttkay-Nedecky, B., Krystofova, O., Nejdl, L. and Adam, V. 2017. Nanoparticles based on essential metals and their phytotoxicity. J. Nanobiotechnology 15: 33.

Saharan, V., Kumaraswamy, R. V., Choudhary, R. C., Kumari, S., Pal, A., Raliya, R. and Biswas, P. 2016. Cu-chitosan nanoparticle mediated sustainable approach to enhance seedling growth in maize by mobilizing reserved food. J. Agric. Food Chem. 64: 6148-6155.

Sarlak, N., Taherifar, A. and Salehi, F. 2014. Synthesis of nanopesticides by encapsulating pesticide nanoparticles using functionalized carbon nanotubes and application of new nanocomposite for plant disease treatment. J. Agric. Food Chem. 62: 48334838.

Sathiyabama, M. and Charles, R. E. 2015. Fungal cell wall polymer based nanoparticles in protection of tomato plants from wilt disease caused by Fusarium oxysporum f.sp. Iycopersici. Carbohydr. Polym. 133: 400-407.

Seisenbaeva, G. A., Daniel, G., Nedelec, J. M. and Kessler, V. G. 2013. Solution equilibrium behind the room-temperature synthesis of nanocrystalline titanium dioxide. Nanoscale 5: 3330-3336.

Sekhon, B. S. 2014. Nanotechnology in agri-food production: an overview. Nanotechnol. Sci. Appl. 7: 31-53.

Servin, A. D. and White, J. C. 2016. Nanotechnology in agriculture: Next steps for understanding engineered nanoparticle exposure and risk. Nanolmpact 1: 9-12.

Shalaby, T. A., Bayoumi, Y., Abdalla, N., Taha, H., Alshaal, T., Shehata, S. et al. 2016. Nanoparticles, soils, plants and sustainable agriculture. In: Nanoscience in Food and Agriculture 1, eds. by S. Ranjan, N. Dasgupta and E. Lichtfouse. pp. 283-312. Springer International Publishing, Cham.

Shahid, M., Pourrut, B., Dumat, C., Nadeem, M., Aslam, M. and Pinelli, E. 2014. Heavy-metal-induced reactive oxygen species: phytotoxicity and physicochemical changes in plants. Rev. Environ. Contam. Toxicol. 232: 1-44.

Sharma, V. K., Filip, J., Zboril, R. and Varma, R. S. 2015. Natural inorganic nanoparticles-formation, fate, and toxicity in the environment. Chem. Soc. Rev. 44: 8410-8423.

Siddiqi, K. S. and Husen, A. 2017. Plant response to engineered metal oxide nanoparticles. Nanoscale Res. Lett. 12: 92.

Stampoulis, D., Sinha, S. K. and White, J. C. 2009. Assay-dependent phytotoxicity of nanoparticles to plants. Environm.Sci. Technol. 43: 9473-9479.

Stone, D., Harper, B. J., Lynch, I., Dawson, K. and Harper, S. L. 2010. Exposure assessment: recommendations for nanotechnologybased pesticides. Int. J. Occup. Environ. Health 16: 467-474.

Sun, D., Hussain, H. I., Yi, Z., Siegele, R., Cresswell, T., Kong, L. and Cahill, D. M. 2014. Uptake and cellular distribution, in four plant species, of fluorescently labeled mesoporous silica nanoparticles. Plant Cell Rep. 33: 1389-1402.

Suriyaprabha, R., Karunakaran, G., Yuvakkumar, R., Prabu, P., Rajendran, V. and Kannan, N. 2012. Growth and physiological responses of maize (Zea mays L.) to porous silica nanoparticles in soil. J. Nanopart. Res. 14: 1294.

Tang, Y., He, R., Zhao, J., Nie, G., Xu, L. and Xing, B. 2016. Oxidative stress-induced toxicity of $\mathrm{CuO}$ nanoparticles and related toxicogenomic responses in Arabidopsis thaliana. Environ. Pollut. 212: 605-614.

Timmusk, S., Seisenbaeva, G. and Behers, L. 2018. Titania $\left(\mathrm{TiO}_{2}\right)$ nanoparticles enhance the performance of growth-promoting rhizobacteria. Sci. Rep. 8: 617.

Tiwari, D. K., Dasgupta-Schubert, N., Villaseñor Cendejas, L. M., Villegas, J., Carreto Montoya, L. and Borjas García, S. E. 2014. Interfacing carbon nanotubes (CNT) with plants: enhancement of growth, water and ionic nutrient uptake in maize (Zea mays) and implications for nanoagriculture. Appl. Nanosci. 4: 577-591.

Tong, Y., Wu, Y., Zhao, C., Xu, Y., Lu, J., Xiang, S. et al. 2017. Polymeric nanoparticles as a metolachlor carrier: water-based formulation for hydrophobic pesticides and absorption by plants. J. Agric. Food Chem. 65: 7371-7378.

Walker, G. W., Kookana, R. S., Smith, N. E., Kah, M., Doolette, C. L., Reeves, P. T. et al. 2017. Ecological risk assessment of nano-enabled pesticides: a Perspective on problem formulation. J. Agric. Food Chem. DOI: 10.1021/acs.jafc.1027b02373. (In press)

Wang, F., Liu, X., Shi, Z., Tong, R., Adams, C. A. and Shi, X. $2016 a$. Arbuscular mycorrhizae alleviate negative effects of zinc oxide nanoparticle and zinc accumulation in maize plants--a soil microcosm experiment. Chemosphere 147: 88-97.

Wang, X., Han, H., Liu, X., Gu, X., Chen, K. and Lu, D. 2012a. Multiwalled carbon nanotubes can enhance root elongation of wheat (Triticum aestivum) plants. J. Nanopart. Res. 14: 841.

Wang, Y.-J., Huang, Y., Anreddy, N., Zhang, G.-N., Zhang, Y.-K., Xie, M. et al. 2016b. Tea nanoparticle, a safe and biocompatible nanocarrier, greatly potentiates the anticancer activity of doxorubicin. Oncotarget 7: 5877-5891.

Wang, Z., Xie, X., Zhao, J., Liu, X., Feng, W., White, J. C. and Xing, B. 2012b. Xylem- and phloem-based transport of CuO nanoparticles in maize (Zea mays L.). Environ. Sci. Technol. 46: 4434-4441.

Watson, J. L., Fang, T., Dimkpa, C. O., Britt, D. W., McLean, J. E., Jacobson, A. and Anderson, A. J. 2015. The phytotoxicity of ZnO nanoparticles on wheat varies with soil properties. Biometals 28: 101-112.

Wilson, M. A., Tran, N. H., Milev, A. S., Kannangara, G. S. K., Volk, H. and Lu, G. Q. M. 2008. Nanomaterials in soils. Geoderma 146: 291-302.

Wright, M., Adams, J., Yang, K., McManus, P., Jacobson, A., Gade, A. et al. 2016. A root-colonizing pseudomonad lessens stress responses in wheat imposed by CuO nanoparticles. PLoS One 11: e0164635.

Wu, L. and Liu, M. 2007. Slow-release potassium silicate fertilizer with the function of superabsorbent and water retention. Ind. Eng. Chem. Res. 46: 6494-6500.

Yadav, T., Mungray, A. A. and Mungray, A. K. 2014. Fabricated nanoparticles: current status and potential phytotoxic threats. 
Rev. Environ. Contam. Toxicol. 230: 83-110.

Yang, J., Cao, W. and Rui, Y. 2017. Interactions between nanoparticles and plants: phytotoxicity and defense mechanisms. J. Plant Interact. 12: 158-169.

Yang, K.-Y., Doxey, S., McLean, J. E., Britt, D., Watson, A., AI Qassy, D. et al. 2018. Remodeling of root morphology by $\mathrm{CuO}$ and $\mathrm{ZnO}$ nanoparticles: effects on drought tolerance for plants colonized by a beneficial pseudomonad. Botany 96: 175-186.

Yuan, Z., Li, J., Cui, L., Xu, B., Zhang, H. and Yu, C. P. 2013. Interaction of silver nanoparticles with pure nitrifying bacteria. Chemosphere 90: 1404-1411.

Zabrieski, Z., Morrell, E., Hortin, J., Dimkpa, C., McLean, J., Britt, D. and Anderson, A. 2015. Pesticidal activity of metal oxide nanoparticles on plant pathogenic isolates of Pythium. Ecotoxi- cology 24: 1305-1314.

Ze, Y., Liu, C., Wang, L., Hong, M. and Hong, F. 2011. The regulation of $\mathrm{TiO}_{2}$ nanoparticles on the expression of light-harvesting complex II and photosynthesis of chloroplasts of Arabidopsis thaliana. Biol. Trace Elem. Res. 143: 1131-1141.

Zhao, L., Huang, Y., Hu, J., Zhou, H., Adeleye, A. S. and Keller, A. A. 2016a. ${ }^{1} \mathrm{H}$ NMR and GC-MS based metabolomics reveal defense and detoxification mechanism of cucumber plant under nanoCu stress. Environ. Sci. Technol. 50: 2000-2010.

Zhao, L., Ortiz, C., Adeleye, A. S., Hu, Q., Zhou, H., Huang, Y. et al. 2016b. Metabolomics to detect response of lettuce (Lactuca sativa) to $\mathrm{Cu}(\mathrm{OH})_{2}$ nanopesticides: oxidative stress response and detoxification mechanisms. Environ. Sci. Technol. 50: 9697-9707. 